\title{
Afterword: Aude Describere!
}

\author{
D. R. KOUKAL
}

Assuming you have navigated the whole of this special topics issue of PhaenEx before reaching this page, you have just finished a phenomenological tour of a paired set of phenomena, "edges" and "the in-between." This tour offered a diversity of starting points—from the coast of Maine to the roadside motel room, from moments of laughter and being startled to the "thinking" of architectural horizons, from the nexus of human and machine to the space and time we occupy during a commute from one place to another. From these starting points, you traversed many paths inspired variously (but far from exclusively) by Heidegger, Levinas, Husserl, MerleauPonty, Nancy, Deleuze, Sartre, Derrida, etc.. In every case, however, each path brought you closer, in its own way, to discerning one or more aspects of the essential structures of these rich phenomena in which we all find ourselves immersed.

You may think it strange, then, to have arrived at the end of this exhilarating journey only to be confronted with an afterword that will seem so at odds with a volume dedicated to doing phenomenology, insofar as it does no phenomenology whatsoever. Given the provocative originality of the preceding analyses and investigations you may well ask, what more needs to be said?

What I offer in the following pages is a reflection that, though expressed from my own perspective, I believe will resonate with those who have traveled a similar professional path, and 
who find themselves in a similar professional place. In the main, this reflection will speak to a certain kind of difficulty involved with doing (or even starting to do) the kind of work represented in this volume. I will maintain that this difficulty has its source in the sort of institutional structures many of us think and write under, which gives rise to a kind of attitude or set of presuppositions that tends to obscure or diminish the worth and promise of attending to the things themselves, phenomenologically. That the contributors to this volume have risen above these structures and this attitude is a testament to their commitment to seeing with unveiled eyes the various edges and in-betweens of the world. Nevertheless, I think it useful to name this particular difficulty and attempt to make it more manifest, for the sake of further advancing similar endeavors in the future. In naming this difficulty, I do not see myself as merely railing against the strictures of academia. Rather, I see myself pointing to a kind of attitude of which we must be aware if we wish to put it aside and return to a lived and living world to describe it as faithfully and as purely as possible. If I may be so bold as to make the following comparison, in this I see myself as doing nothing different from what Husserl does when he warns us of the reductionistic tendencies of naturalism, and when he points to the natural and theoretical attitudes as barriers to seeing the world primordially (Husserl, "Philosophy" 87). I too will offer a warning in this connection; but in what follows you will also find autobiographical elements of confession and conversion, as well as a call and a challenge. There is, then, an Augustinian aspect to what I write here, but whereas this saint's divine muse told him to "take up and read!" in Book VIII of his Confessions, you will find that my call is for more phenomenologists not only to read, but also to look up from their pages and dare to see for themselves that world about which they read, and write, with purified eyes. ${ }^{1}$ 


\section{Confession}

I confess that while on my way to becoming a professional philosopher, I became increasingly forgetful of the larger world from which I had departed. My move toward this forgetfulness began innocently enough. A combination of experiences, too tangled and faded in memory to recount here, stimulated in me a passion that drew me into an intense engagement with the intellectual aspects of this world, the world of ideas. As this engagement endured and grew in intensity, I immersed myself further in this passion, eventually focusing on the discipline of philosophy, which to my mind spoke to this world in a singular way. After five years of study I decided to bring my passion into sharper focus through further and deeper scholarship. During this period I discovered phenomenology, and for years I worked to master this way of thinking through a deep immersion in and adherence to the scholarly method of careful exegesis and criticism of the relevant texts in the field. This intellectual activity was aimed, first, at a better understanding of this literature, which would then hopefully reveal its relevance to the wider and lived world that was the original source of my passionate calling as a scholar-and, I might add, the original source of all scholarship whatsoever.

However, during the later stages of my doctoral training, I found myself in a strange place. I found myself among highly intelligent and motivated people whose higher education allowed them to hold forth in extended, erudite and subtle conversations about the objects of their various passions, but who, because of their intense focus on a given figure, problem or subset of problems, often ended up in separate and insular academic enclaves, rarely speaking with learned brothers and sisters even in neighboring areas of scholarship. I should quickly add that I was not a stranger in this strange place. I too, over the course of my academic training, had slowly given myself over to the practice of tending to speak only with those holding similar 
concerns in very narrowly circumscribed areas of scholarship. I too would often become fixated on exegesis and critique relevant to my own particular scholarly concerns, resulting in my trafficking in arid, textual obscurities purged of the original passion that had once animated me to pursue my academic interests in the first place. In my scholarly absorption I had largely forgotten the wider world from which I came-and, in retrospect, I cannot blame it if it forgot about me.

I hasten to add that exegesis and critique are deeply essential in coming to terms with phenomenology. Husserl possesses an intimidating breadth of philosophical vision; he sees phenomenology as being not only a "first" philosophy which all other philosophies must acknowledge, but also as a rational discipline with fundamental relevance to all of the alreadyestablished sciences and every human activity. Moreover, Husserl's various theoretical progeny, most of whom are challenging theorists in their own right, have taken phenomenology in radically different directions. In short, textual explication in phenomenology is unavoidable; the central texts of this school of thought are formidably dense, and the insights within are sophisticated and subtle. To the extent that I can declare myself a phenomenologist, I can only make this declaration to the degree that I have personally engaged with the difficult texts that make up this complex tradition, an engagement which persists to the present day as this tradition continues to evolve.

\section{Warning}

Yet there is another, perhaps more insidious and subterranean factor involved in my deep engagement with phenomenology's texts, one that has its source in the structure of the academy where I "became" a phenomenologist. The contemporary university has, since the age of 
modernity, become highly compartmentalized, even Balkanized, due to the segmentation of human knowledge in the name of specialization. Trained as a generalist as an undergraduate, I was very quickly made to understand that in graduate school I needed to specialize. Whether I was doing coursework or writing a dissertation prospectus, I understood this to mean that in my work I should pick a narrowly construed problem within my narrowly circumscribed area of study, master the most important and especially the latest critical commentary, and "make an original contribution," however small, to the existing scholarship on this narrowly construed problem. I contend that this intense focus on the textual minutiae of our various areas of study to the exclusion of all else is an almost inevitable result of our doctoral training. Again, I do not want to appear critical of this kind of rigorous scholarship. A good deal of it sheds bright light on dark and difficult texts; I would even humbly claim to have made some minor contributions in this regard. What I wish to emphasize here is the general orientation of this kind of scholarship: inwards, towards the near horizon of our texts, as opposed to outwards, toward the far horizon of the world which is the originary source of all our scholarship, texts, and wonder.

This is not to say that my freedom of thought was constrained by my training. I was totally free, of course, to let my mind wander to consider the interdisciplinary dimensions of my work, or how my textual musings, critiques and interpretations might again find purchase in a lived world. But to the extent that my training conveyed to me the "lay of the land" as to what was publishable in my chosen profession, over time it did instill in me a sense of what I should and should not write. Scholars, particularly younger scholars, ignore this lay of the land at their peril, as it is intertwined with matters concerning advancement in their various fields.

What I have been trying to describe, and what I want to bring into sharper relief at this point, is a mostly unacknowledged barrier to undertaking phenomenological descriptions, over 
and beyond the natural and theoretical attitudes to which Husserl points, attitudes that he insists we bracket and put aside in order to make our consciousness ready for phenomenological reflection. I will call this barrier the "exegetical attitude," a habit of mind wherein we mistake a high degree of fluency with phenomenological texts within the structures and strictures of various academic institutions for the whole of phenomenology itself.

As I have already suggested, the exegetical attitude is no stranger to anyone who has spent any time engaged in the professional world of the academy, either as a graduate student or as a member with full accreditation. I have seen this attitude manifested in the due diligence of my detailed footnotes, in my duly-executed survey of the major commentaries and seminal figures on the issues I write about, and within the confines of the many professional conferences where I have engaged in the explication of various "problems" encountered within the writings of various thinkers and schools of thought.

Once again I must stress that I have a deep appreciation for what this scholarship has accomplished, and continues to accomplish. But over time, I also became aware of how this inward-pointing orientation towards texts has generated certain institutional structures that tend to favor this orientation to the exclusion of other possible orientations. Two incidents crystallized this realization for me. Not long after earning my doctorate, I told a senior and very respected colleague in the field of my growing desire to produce actual reflective sketches based on that which appeared to my consciousness within a phenomenological attitude. His immediate response was, "But where would you publish them?" The other incident came immediately following the defense of my dissertation, which dealt with the methodological problem of communicating the insights gained through transcendental phenomenology to the larger world. 
During the question period, I was asked quite earnestly by a close friend and fellow doctoral student why phenomenology would want to speak to the rest of the world.

In both instances I was brought up short. I was not especially articulate in my responses, but these comments provoked in me a long period of reflection which continues to this day, a reflection which has attempted to situate phenomenology considered both as an area of scholarship and a way of seeing within the larger philosophical academy. In regards to the first incident, I have come to realize that my senior colleague was merely giving me the conventional advice as to what more junior scholars like myself should be doing at that point in their career: reading the relevant texts deeply and critically, writing and presenting good papers at good conferences, and publishing these papers in good journals or as a monograph, thereby reaping the rewards of employment, promotion and tenure. My colleague's advice-and it was not offered all that long ago - points to a concern with career that cannot be so easily dismissed in a difficult philosophical job market, especially for a phenomenologist seeking a position in a country where the analytic tradition predominates. But I want the reader to consider the deeper presuppositions underlying this advice. My senior colleague, who is highly accomplished in phenomenology and the broader continental tradition, clearly did not think that the phenomenological reflections I desired to generate were publishable by any of the respectable continental journals or presses. This, to my mind, can only be interpreted in one way: phenomenology considered as an area of philosophical scholarship is worthy of publication; phenomenology as a way of seeing is not. And if this is the case, then it would seem to follow that practicing phenomenology as a way of seeing is not considered "real" phenomenology, at least as far as the continental philosophical academy is concerned. 
If my senior colleague's assessment of the publishability of phenomenological reflections is widespread, then this would be a testament to the exegetical attitude having become sedimented into the structure of this part of the philosophical academy. It is in this context that the question asked by my friend (and now colleague) at my defense can be better understood. In my view, the implications of his question were two-fold: why would people want to hear what phenomenologists have to say, and why would we phenomenologists want to talk to nonphenomenologists anyhow? The question, and its implications, does more than illustrate how the exegetical attitude imbedded in the structure of the academy reproduces this attitude in those who labor within it. It also shows how this attitude lends itself to an inward-directed insularity towards the texts in our near horizon, to the neglect of the far horizon of the world, and, in my view, to the impoverishment of phenomenology.

\section{Conversion}

My reading of the western tradition of philosophy tells me that the exegetical attitude has a long history, and that this attitude has periodically nettled various thinkers, who have generated movements to counter this trend. The first and most obvious among these would be Descartes, who in the Discourse eventually comes to criticize the Schoolmen's way of philosophy and advocates for knowledge that was "useful for life" (Discourse 33) followed closely by Hobbes's scornful empiricism in Leviathan. In their turn, Rousseau's proto-Romanticism, Marxist social analysis, pragmatism, logical positivism and existentialism (to name only the most obvious examples) have all sought, each in their own way, to reunite philosophical activity with the activity of life. 
Phenomenology should certainly be counted as yet another attempt to bring philosophy back to the world, in the face of the reductionism of the natural sciences. It may also perhaps be the most comprehensive, since it claims that the explanatory dimension of all of the various theoretical disciplines must necessarily have their ultimate grounding and unity in a descriptive realm of a single lived world. The most exciting aspect of phenomenology is its fundamental claim that it is a philosophy which contacts life and does so directly, thereby allowing us the possibility of seeing it again, as if for the first time. In this phenomenology is not a speculative system or a school of thought that we are enhancing and defending in the memory of Husserl or Heidegger or Merleau-Ponty. It is, first and foremost, a manner of philosophical practice, a human activity that allows us to see the world again in a primordial fashion. The aim of phenomenology has always been to bring philosophy back to the larger world, that is, to describe the relationship between lived experience and consciousness, without necessarily turning to theories or other conceptual constructs that are typically employed to "explain" experience.

Unfortunately, however, an unscientific survey of the respectable continental journals and university press catalogues suggests to me that on balance the continental philosophical academy regards phenomenology for the most part as an area of philosophical scholarship, while forgetting that it is also a way of seeing. This is no small irony within a tradition that takes its cues from various unfortunate "forgettings" (the forgetting of the primordial, pre-theoretical realm of experience, the forgetting of the question of the meaning of Being, etc.). It seems as though phenomenology itself has unfortunately forgotten the original insights which laid its groundwork.

This calls to mind what Husserl describes in his "Origin of Geometry" essay: as an area of knowledge matures and its original insights are set down, absorbed and constantly reiterated, 
these words come to be passively taken over and accepted as self-evident, but only at the level of understanding an expression, and not the original insight which inspired the expression. As a body of knowledge continues to evolve and grow through these associative modes of communication-e.g., through the constant publication of critical and exegetical commentaries, professional conferences, etc.- - it only passively appropriates its own foundation, which is based on distant and primal self-evidences. As the body of knowledge continues to grow, our capacity for actually experiencing the original insight that inspired the foundation on which the scholarly edifice rests is greatly diminished (Husserl, Crisis 361-365). In the "Origin of Geometry," Husserl gives us a deep genealogy of the exegetical attitude.

There is an even deeper irony in the fact that we all came to phenomenology through texts; it's not as if there are many of us left who attended Husserl's seminars or who heard Merleau-Ponty's inaugural lecture at the Collège de France. Even then, one would have had to listen very attentively to understand what each was trying to convey about phenomenology's radical project. If one's curiosity had been sufficiently stimulated by the seminar or lecture, one may have gone on to read Ideas I or Phenomenology of Perception, and perhaps some of the extant first-generation commentary. And even then, even if one had been intellectually inspired by the ideas and insights on these pages, one would still not have been fully able to appreciate the scope and import of phenomenology's promise unless one had attempted to practice phenomenology, not just as an area of scholarship, but also as a way of seeing. The mistake is to take exegesis as the whole of phenomenology, when it is only a part-a vitally important part to be sure, but still only a part. The exegetical and the experiential should not be viewed as being frozen in binary opposition, but rather as complementary terms located along a continuum. Over the one hundred years since phenomenology's inception, we have brought much scholarly rigor 
to its founding texts; it is now time to develop a rigor in the phenomenological seeing of lived experience that these texts sought to inspire. To repeat Husserl's famous dictum, let us return to "the things themselves" to see phenomena in a purified way, and then think and talk and write about the phenomena we see. Otherwise, it will be as if we have hastened to the museum to see the impressionists, who promised a new way of seeing the world, and then spent all our time reading the placards next to the paintings rather than looking at the paintings themselves.

\section{A Call and a Challenge}

I hope it is clear at this point that what I am proposing is not a subordination of phenomenological scholarship to phenomenological seeing. I am, rather, advocating a recovery of the animating spirit of phenomenology through the use of this scholarship in a way that allows more phenomenologists to engage in phenomenological seeing by freeing them from their exegetical habits, while retaining the insights gained through these same habits of exegesis.

The animating spirit to which I refer is perhaps best captured by a story often told about how Sartre was introduced to phenomenology. Just before the Second World War, Sartre, Simone de Beauvoir, and Raymond Aron were enjoying an evening at the Bec de Gaz where they all ordered the specialty of the house, apricot cocktails. Aron, who had studied phenomenology in Berlin, introduced the idea to Sartre by pointing to his glass and saying to him, "You see, my dear fellow, if you are a phenomenologist, you can talk about this cocktail and make philosophy out of it!" Sartre reportedly turned pale with emotion at this. Here was just the thing he had been longing to achieve for years- to describe objects just as he saw and touched them, and extract philosophy from the process. From this moment on, Sartre's thought 
was animated by the spirit if not the letter of phenomenology (Schmidt, Maurice Merleau-Ponty 112; de Beauvior, Prime 17-18; Moran, Introduction 5, 359).

If we are to take this story at face value, Sartre was a phenomenological novice when Aron gestured toward his cocktail glass. Sartre had not yet developed an exegetical knowledge of Husserl and Heidegger, as we now know he did, and in very short order. But in this pure, naïve moment of apprehension he was able to grasp the essence of phenomenological seeing, without the benefit of such knowledge. Now this is not to say that Sartre had no need of such knowledge; in fact, without it, he would have never been able to achieve his own unique readings of Husserl and Heidegger, nor would it have been possible for him to write Being and Nothingness. At the same time, he was able to take what he learned from Husserl and Heidegger into his own seeing, which resulted in some of the most original work in the phenomenological tradition. If I may paraphrase Descartes: like us, Sartre was thrown into the world, he discovered (through Aron) the world of some particular books, and then, turning back with the insight gleaned from these books, he began to read the book of the world with fresh eyes.

Perhaps one way to "bracket" the exegetical attitude would be to try to imagine ourselves as Sartre, the phenomenological neophyte, who saw the promise of phenomenology before he could phenomenologically see. Or, perhaps even better, we could imagine ourselves to be Aristotle, who, despite not being a phenomenologist in the purest sense (his metaphysical commitments alone would seem to preclude such a possibility), was able generate phenomenological insights outside the scholarly conventions of the modern university, which seem to require so much of our attention and which, in the worst cases, constrict the parameters of our thinking and our modes of expression. Imagine what it would be like to put these conventions aside and simply confront the world as it appears, and to focus the fullness of one's 
attention on its different aspects and dimensions. (Think of the cocktail glass!) While it is true that Aristotle typically begins a work by acknowledging the contributions of his most important predecessors, he always manages to do this in a concise summary that captures the essence of their ideas before he moves on to the topic at hand. Even when he is building on what came before, Aristotle builds without reciting, and most of his work is his work, his thinking-and there is no reason that we cannot do the same when we do phenomenology. Once Aristotle has briefly surveyed the ground upon which he is to build, only then does turn to begin his own philosophizing. In this he follows his teacher, who famously declared that "philosophy begins in wonder" (Plato, Theaetetus 155d; Aristotle, Metaphysics 982b12), a declaration that found its way into the mouth of Eugen Fink over two millennia later, when he spoke of wonder in the face of the world in reference to Husserl's notion of the reduction (Merleau-Ponty, Phenomenology xiii). I would like to think I've experienced such wonder on the occasions when I have put aside my books for a time, to directly reflect on an aspect of experience as purely as I could.

I hope it is clear that the sharp distinction I have made between phenomenological scholarship and phenomenological seeing in this essay was for the purposes of analysis only; in reality, to say that we have to choose between the two is a false choice. There is, in fact, nothing to prevent us from putting the different versions of phenomenology's method into practice, even while we debate amongst ourselves the various ways of reading primary phenomenological texts and the vast critical apparatus issuing from them. Indeed, I think that such practice can be of service to these debates as a way of testing different "readings" of phenomenology against the experience of phenomenological seeing. In this way we can further refine these various methods in order to further explore phenomenology's still largely unrealized potential as a method of rational inquiry in-the-world, which is only limited by life itself. 
There have, in fact, been periodic flourishings of phenomenological practice in recent years (Grant, "Practical Intersubjectivity" 560-567). The Society for Phenomenology and the Human Sciences (SPHS) has long been a congenial home for scholars seeking to promote interdisciplianry and phenomenological inquiry into lifeworld activities and practices (Society for Phenomenology and the Human Sciences), and it is gratifying to see the recent publication in book-length form of various phenomenological analyses generated by senior and independent scholars. ${ }^{2}$ The French group "Alter" was founded in the early 1990s by a small group of international researchers who shared an interest in a communal style of inquiry, and has generated several substantial annual reviews of phenomenological research centered on various themes (Steinbock 65). The recent appearance of Phenomenology \& Practice, a journal dedicated to the study of the lived experience of a broad range of human practices, is extremely encouraging, as is the very favorable attention received by the various "postphenomenological" research projects organized by Don Ihde ("Postphenomenological" 1-9). These recent developments, when considered alongside the persistence of various efforts over the years to engage phenomenology as a way of seeing, may well indicate that the continental philosophical academy is slowly but surely becoming more receptive to the idea that phenomenology is much more than just an area of philosophical scholarship.

As for myself, there is nothing more liberating and exhilarating than when I've relegated my exegetical knowledge to deep background and am engaged in exploring an aspect of experience through phenomenological reflection. I have discovered that this kind of engagement, more often than not, yields unexpectedly fecund insights into a world hidden beneath scientific explanations and other conceptual constructs. I have found that through phenomenology, philosophy can come to life again—not just for philosophers, but potentially also for all of the 
rich variety of human experience. Husserl makes it clear that it is essential to phenomenology's task to communicate its insights to the various regions of human activity which it claims to ground through its activity. In doing so, phenomenology invites all of humanity to return to a primordial realm of experience that underlies all of our preconceptions of these different regions, so that it may have a deeper understanding of the lived world common to all. But if this invitation to understand this primordial realm is to be extended by phenomenologists, more of us must first find our way back from the world of the book and return to the book of this veiled and forgotten world, and then, audaciously, dare to describe what we discover there.

\section{Notes}

${ }^{1}$ Many thanks to the two PhaenEx blind reviewers for their frank and rigorous criticisms of the first draft of this Afterword.

2 See, for example, Edward S. Casey, Getting Back Into Place; David Abrams, The Spell of the Sensuous; and H. Peter Steves, The Things Themselves, to name only a few.

\section{Works Cited}

Abrams, David. The Spell of the Sensuous. New York: Vintage Books, 1997.

Aristotle. Metaphysics. Trans. W. D. Ross. In The Complete Works of Aristotle. Ed. Jonathan Barnes. Princeton: Princeton University Press, 1991.

de Beauvoir, Simone. The Prime of Life. Trans. P. Greene. New York: Harper and Row, 1976.

Casey, Edward S. Getting Back Into Place. Bloomington: Indiana University Press, 1993.

Descartes, René. Discourse on Method. Trans. Donald A. Cress. Indianapolis: Hacket Publishing Company, 1980

Grant, Stuart. "Practical Intersubjectivity.” Janus Head 8, no. 2 (2005): 560-580. 
Husserl, Edmund. "Philosophy as a Rigorous Science." Phenomenology and the Crisis of Philosophy. Trans. Quentin Lauer. New York: Harper \& Row, 1965.

—. Ideas I. Trans. F. Kersten. Dordrecht, The Netherlands: Kluwer Academic Publishers, 1982.

—. The Crisis of European Sciences and Transcendental Phenomenology. Trans. David Carr. Evanston: Northwestern University Press, 1970.

Ihde, Don. "Introduction: Postphenomenological Research." Human Studies 31, no. 1 (2008): $1-9$.

Merleau-Ponty, Maurice. Phenomenology of Perception. Trans. Colin Smith. London: Routledge \& Kegan Paul, 1962.

Moran, Dermot. Introduction to Phenomenology. London: Routledge, 2000.

Phenomenology \& Practice. 25 October 2008. < http://phandpr.org/index.php/pandp>.

Plato. Theaetetus. Trans. F. M. Cornford. In The Collected Dialogues of Plato. Eds. Edith Hamilton and Huntington Cairns. Princeton: Princeton University Press, 1989.

Schmidt, James. Maurice Merleau-Ponty: Between Phenomenology and Structuralism. New York: St. Martin's Press, 1985.

Society for Phenomenology and the Human Sciences. 25 October 2008. $<$ http://pages.slu.edu/faculty/harriss3/SPHS $>$.

Steinbock, Anthony J. Review of Alter: Revue de phénoménologie (Éditions Alter) (180 ff): No. 1 "Naître et mourir" 1993 (493 pp); No. 2 "Temporalité et affection” 1994 (459 pp); No. 3 “L'animal” 1995 (539 pp). In Husserl Studies 16 (1999): 65-75.

Steves, H. Peter. The Things Themselves. Albany: State University of New York Press, 2006. 